\title{
Manajemen Stres untuk Menurunkan Kecemasan Menghadapi Ujian Nasional Siswa Sekolah Menengah Pertama
}

Friandry W Thoomaszen dan Murtini

Sekolah Tinggi Agama Kristen Negeri (STAKN) Kupang Jl. Cak Doko No. 76, Kampung Baru, Kupang - 85112, Nusa Tenggara Timur.\& Fakultas Psikologi Universitas Gadjah Mada. windisany90@gmail.com

\begin{abstract}
Students experienced anxiety and fear when facing the National Exam because they think it is pressed. In addition, it is caused by the lack of the resources to deal with the final exam. The research aim was tested the stress management training based on the procedure of Stress inoculation training (SIT) in the junior high school students who experienced anxiety facing the final exam. The research hypothesis was that stress management training could reduce the anxiety facing the final exam at the Junior High School students. The scale questionaire used to measure the anxiety. The research method was quasi-experiment. The results of analysis with the mixed ANAVA technique showed that the stress management training by the SIT procedure could significantly decreased anxiety when facing the final exam in junior high school students in Kupang $(F=17.192, p<0.01)$, with the effective contribution about $86.7 \%$. Junior high school students who had received the stress management training decreased level of anxiety to face the final exam more significantly than those who did not received the stress management training.
\end{abstract}

Key word: adolescence, anxiety, stress management.

\begin{abstract}
ABSTRAK
Murid mengalami kecemasan dan ketakutan menghadapi Ujian Nasional. Sumber kecemasan berasal dari pikiran murid bahwa situasi UN menekan dan kekurangan sumber daya untuk menghadapi UN. Tujuan penelitian adalah melakukan uji coba pelatihan manajemen stres berdasarkan prosedur Stress Inoculation Training (SIT) pada murid SMP yang mengalami kecemasan menghadapi UN. Hipotesis penelitian yaitu pelatihan manajemen stres dapat menurunkan kecemasan menghadapi UN pada murid tingkat SMP Negeri. Alat untuk mengukur kecemasan pada murid yaitu skala kecemasan menghadapi UN. Metode penelitian adalah eksperimen-kuasi. Hasil analisis dengan teknik anova campuran menunjukan bahwa pelatihan manajemen stres berdasarkan prosedur SIT secara signifikan dapat menurunkan kecemasan menghadapi UN pada murid SMPN di Kupang $(\mathrm{F}=17,192 ; \mathrm{p}<0,01)$, dengan sumbangan efektif sebesar 86,7\%. Murid SMP yang mendapatkan pelatihan manajemen stres mengalami penurunan tingkat kecemasan menghadapi UN yang signifikan dibandingkan dengan murid yang tidak mendapatkan pelatihan manajemen stres.
\end{abstract}

Kata kunci: kecemasan terhadap ujian, manajemen stres, remaja. 


\section{PENDAHULUAN}

Pemerintah Indonesia telah melaksanakan Ujian Nasional (UN) sejak tahun 2003. Murid dikatakan lulus pada suatu jenjang pendidikan ketika nilai UN memenuhi kriteria kelulusan yang telah ditetapkan oleh pemerintah. Pada setiap tahun, kriteria kelulusan Ujian Nasional mengalami perubahan peraturan dan kenaikan nilai (standar). Pada tahun 2011/2012, Peraturan Menteri Pendidikan dan Kebudayaan Nasional Nomor 59 tahun 2011 mengatakan bahwa kriteria kelulusan peserta didik dari UN SMP/ MTs berdasarkan perolehan Nilai Akhir (NA). Nilai Akhir (NA) adalah nilai gabungan antara Nilai Sekolah (NS) dari setiap mata pelajaran dan Nilai UN. Dengan pembobotan 40\% untuk NS, dan $60 \%$ untuk Nilai UN. Peserta didik SMP/MTs dinyatakan lulus UN apabila nilai ratarata dari semua NA mencapai paling rendah 5,5 (lima koma lima) dan nilai setiap mata pelajaran paling rendah 4,0 (empat koma nol).

Survei yang dilakukan oleh Center Public Mental Health (CPMH) Fakultas Psikologi Universitas Gadjah Mada (2010) di Kabupaten Sleman Yogyakarta, didapati data bahwa 44,9\% siswa SMP Negeri berada pada tingkat kecemasan tinggi dalammenghadapi UN. Peneliti memilih subjek penelitian murid SMP Negeri yang berada antara tahap perkembangan remaja awal dan tengah, 10-16 tahun (Santrock, 2007). Pada tahap tersebut, mereka menghadapi banyak tuntutan dan perubahan yang cepat sehingga mereka rentan mengalami masa yang penuh kecemasan. Ujian Nasional merupakan salah satu sumber kecemasan murid berkaitan dengan aktivitas sekolah.

Pada bulan Juni 2012, peneliti melakukan studi pendahuluan tentang kecemasan menghadapi UN di SMP Negeri kota Kupang. Hasil wawancara dengan pihak sekolah yaitu setiap murid pasti mengalami kecemasan menghadapi UN. Menurut guru, faktor penyebab murid mengalami kecemasan menghadapi UN terdiri dari tiga bagian yaitu pihak sekolah (guru), pihak keluarga, dan pihak murid. Peneliti berfokus meneliti tentang persepsi murid terhadap situasi UN, karena berdasarkan pendekatan kognitif behavior, persepsi yang negatif dapat mempengaruhi kecemasan menghadapi UN. Sumber utama terjadi kecemasan menghadapi UN yaitu penilaian murid tentang situasi $U N$ yang mengancam keberhasilan dan hasil belajar. Persepsi negatif murid dapat terbentuk dari penilaian murid dan tuntutan lingkungan. Cara mengajar guru, kurikulum, kurang fasilitas dari orangtua, dan pola hubungan orangtua yang kurang baik termasuk tuntutan lingkungan.

Hasil wawancara dengan 20 murid kelas IX SMP N Kupang menunjukan bahwa setiap murid merasakan gugup, khawatir, gelisah, takut, dan kurang yakin dalam menghadapi UN. Gejala kecemasan sudah dirasakan ketika memasuki semester 2 kelas IX. Intensitas kecemasan semakin tinggi ketika UN semakin dekat. Pada hari pertama pelaksanaan UN, murid berada pada titik puncak kecemasan dan semakin berkurang pada hari berikutnya. Penyebab murid mengalami puncak kecemasan pada hari pertama UN karena sebelum UN berlangsung murid memiliki penilaiannegatif(situasi UNmenakutkan dan menekan) hingga mengalami khawatir yang berlebihan. Pikiran murid menyebabkan munculnya reaksi kecemasan seperti takut tidak lulus UN, takut salah menjawab soal UN, dan takut kurang teliti menghitamkan lingkaran jawaban sehingga tidak bisa terbaca oleh komputer.

Kesimpulan studi pendahuluan yaitu kecemasan menghadapi UN terjadi karena pandangan murid tentang UN yang menekan dan sumber daya pribadi yang kurang seimbang dengan tuntutan. Jika muridmemiliki pengetahuan tentang strategi koping yang tepat untuk beradaptasi dengan tuntutan UN yang menekan maka murid dapat mengelola kecemasan menghadapi UN. Oleh karena itu, murid perlu program yang memberikan pengetahuan 
mengelola tuntutan UN dan mengurangi sumber kecemasan. Dengan program tersebut dapat mendukung murid agar mampu mengelola situasi yang menekan dan tuntutan dari lingkungan dengan berpikir positif bahwa situasi UN merupakan hal yang menantang.

Situasi UN berpotensi menimbulkan reaksi stres karena adanya tuntutan dari lingkungan yang harus murid hadapi. Situasi UN juga berpotensi menimbulkan reaksi kecemasan karena murid memberikan interpretasi pada situasi UN. Ketika murid menilai situasi UN mengancam, menekan, dan berbahaya dapat mempengaruhi tingkat kecemasan murid dalam menghadapi UN. Lazarus dan Folkman (1984) mengatakan stres dan kecemasan saling berkaitan, karena adanya transaksi antara individu dan lingkungan (pandangan transaksional). Stres yang berlebihan akan menyebabkan munculnya kecemasan. Stres yaitu hasil (akibat) dari ketidakseimbangan antara tuntutan dan kemampuan. Stres berkaitan dengan reaksi emosional yang spesifik. Lazarus (1991) menyebutkan kecemasan merupakan salah satu emosi dasar yang negatif.

Menurut Lazarus (1990), kecemasan adalah respon individu terhadap situasi-situasi yang menakutkan. Kecemasan adalah emosi yang muncul terkait dengan bahaya, termasuk adanya keinginan untuk terlepas dan terhindar dari bahaya. Kondisi bahaya yang dimaksudkan adalah bahaya yang bersifat psikis, terkait dengan serangan terhadap identitas seseorang. Reaksi yang muncul pada saat cemas antara lain adalah perasaan yang tidak jelas, tidak berdaya, dan tidak pasti apa yang akan dilakukan. Lazarus (1991) mengatakan kecemasan muncul ketika makna eksistensi seseorang terganggu atau terancam sebagai hasil dari ketidakmampuan fisik, konflik intrapsikis, dan peristiwa yang sulit didefinisikan. Hal yang membuat murid merasa takut karena situasi UN bersifat simbolik. Arti simbolik yaitu situasi masa mendatang yang belum terjadi dan tidak pasti keadaannya. Kecemasan terjadi berdasarkan tujuan personal, keyakinan, dan penilaian kognitif. Penilaian kognitif merupakan mediasi antara individu dan lingkungan. Penilaian dan interpretasi terhadap situasi UN yang memunculkan kecemasan menghadapi UN (Lazarus \& Folkman, 1984). Jadi kecemasan menghadapi UN yaitu reaksi emosional yang tidak menyenangkan sebagai hasil dari penilaian situasi UN yang mengancam pribadi (Lazarus \& Folkman, 1984).

Dua konsep utama dari teori stres dan kecemasan Lazarus (1991) yaitu penilaian kognitif dan koping. Dua tahap penilaian kognitif yang berperan dalam mekanisme terjadi kecemasan menghadapi ujian yaitu penilaian primer dan sekunder (Lazarus, 1991). Penilaian primer adalah penilaian atau evaluasi terhadap situasi yang terjadi, dianggap sebagai sesuatu yang membahayakan (harm), mengancam (threat), atau menantang (challenge). Situasi UN dianggap membahayakan ketika murid menilai bahaya yang diperoleh dari situasi UN. Situasi UN dianggap mengancam ketika murid menilai kemungkinan buruk atau ancaman dari situasi UN. Situasi UN dianggap menantang ketika murid merasa sanggup mengatasi dan mendapatkan keuntungan dari situasi UN. Pola penilaian primer yaitu adanya pertemuan antara tujuan personal dengan situasi UN. Murid merasa situasi UN menghalangi mencapai tujuan personal (goal incongruence). Kecemasan menghadapi UN terjadi ketika murid berhadapan dengan situasi yang tidak pasti dan mengancam eksistensi. Penilaian sekunder adalah penilaian terhadap sumber daya yang dimiliki, beserta kemampuan murid melakukan koping. Sumber ini selanjutnya akan digunakan untuk mengatasi situasi UN.

Lazarus dan Folkman (1984) mengatakan koping adalah proses mengelola tuntutan (internal atau eksternal) yang dianggap sebagai beban dan di luar kemampuan individu. Koping melibatkan individu untuk berubah secara kognitif dan perilaku sebagai upaya untuk mengelola (mengurangi, meminimalkan, menguasai, mentoleransi) tuntutan internal dan eksternal yang 
dinilai sebagai stres. Koping terhadap situasi ujian terdiri atas upaya yang berorientasi kegiatan dan intrapsikis untuk mengelola tuntutan internal atau eksternal, seperti menuntaskan tugas, mengatur waktu belajar, ketekunan, kesabaran, dan berpikir positif.

Menurut Lazarus dan folkman (1984), ada dua strategi dalam melakukan koping yaitu koping yang berfokus pada masalah (problem-focused coping) dan berfokus pada emosi (emotionfocused coping). Penelitian Stowell, Tumminaro, dan Attarwala (2008) menemukan murid dengan kecemasan menghadapi ujian yang tinggi gagal dalam menggunakan koping yang berfokus pada penyelesaian masalah. Hal ini berarti, murid pencemas kurang mempunyai pengetahuan tentang strategi belajar yang efektif sehingga berdampak pada hasil belajar yang kurang maksimal. Murid SMP cenderung menggunakan strategi koping yang berfokus pada emosi (Griffith dkk, 2000; Magaya dkk, 2005). Murid mengalami kecemasan menghadapi ujian karena kurang mendapatkan dukungan, ketidakmampuan dalam menilai situasi yang dianggap menekan, dan kurang keterampilan koping dengan ancaman (Rutter, Kim-Cohen, \& Maughan, 2006; Kraag, Gerard, Breukelen, Kok, \& Hosman, 2009).

Kecemasan ujian pada tingkat yang sedang dan rendah dapat memberikan efek positif pada hasil belajar murid. Elliot, Kratochwill, Littlefield, dan Travers (1999) mengatakan bahwa kecemasan dalam tingkat rendah dan sedang berpengaruh positif pada performansi belajar murid karena dapat meningkatkan motivasi belajar murid. Sarason (1980) menjelaskan bahwa murid yang berada pada level kecemasan terhadap ujian yang rendah akan lebih berhasil dalam melengkapi tugas yang rumit dan waktu ujian yang terbatas. Masalah kecemasan menghadapi ujian terus terjadi di setiap tahun, berbagai daerah, dan memberikan akibat pada kesuksesan akademik. Oleh karena itu, diperlukan suatu program preventif dengan tujuan mencegah dan mengurangi kasus kecemasan terhadap ujian yang terjadi pada murid SMP. Hembree (1988) mengatakan dengan pengenalan program pengurangan kecemasan terhadap ujian (preventif) sejak dini dapat memberikan manfaat yang bermakna bagi pelajar pada jenjang pendidikan selanjutnya. Murid SMP perlu diberikan program yang memberikan pengetahuan dalam mengelola (mengatur) situasi UN yang dianggap menekan. Kemampuan mengelola (manajemen) stres berkaitan dengan istilah koping. Menurut Lazarus dan Folkman (1984), manajemen stres merupakan suatu upaya untuk merubah pikiran negatif dan kemudian muncul tindakan (perilaku) untuk mengatasi tuntutan internal atau eksternal yang dinilai membebani atau melebihi sumber daya yang dimiliki individu. Koping dikatakan efektif jika individu mampu untuk mentoleransi, menerima situasi yang menekan, dan tidak mengkhawatirkan tekanan yang tidak dapat dikuasainya.

Berdasarkan temuan tersebut, peneliti merancang suatu program mengurangi kecemasan murid SMP terhadap ujian. Teknik intervensi dengan pendekatan kognitif behavioral merupakan salah satu perlakuan yang efektif untuk mengatasi kecemasan menghadapi ujian (Neuderth, Jabs, \& Schmidtke, 2009; Ergene, 2003). Tipe intervensi dari Pendekatan kognitifbehavioral yang dikembangkan adalah modifikasi kognitif-behavioral (cognitive-behavioral modification) dan Stress-Inoculation Training (SIT) (Zeidner, 1998; Ergene, 2003). Dalam penelitian ini, intervensi yang dipakai untuk menurunkan kecemasan menghadapi UN adalah pelatihan manajemen stres berdasarkan prosedur SIT, karena SIT termasuk dalam program preventif kasus stres dan kecemasan terhadap ujian. SIT merupakan program manajemen stres yang dikembangkan oleh Meichenbaum (1985).

Pelatihan manajemen stres berdasarkan pendekatan kognitif behavioral Meichenbaum (1985). Prinsip pendekatan kognitif behavioral 
yaitu kognisi individu mempunyai peran signifikan dalam perkembangan dan pengelolaan reaksi emosi dan perilaku terhadap situasi kehidupan. Proses kognisi seperti memberikan arti, penilaian, dan asumsi yang diasosiasikan dengan kejadian hidup yang spesifik, merupakan faktor penentu utama dari perasaan dan tindakan individu terhadap kejadian. Proses tersebut juga dapat mempermudah atau menghalangi proses adaptasi terhadap kejadian hidup. Dasar asumsi program pelatihan (Meichenbaum, 1977) yaitu melakukan pencegahan dan memberikan pendidikan kesehatan psikologis. Pertama, pendidikan kesehatan psikologis dan keterampilan koping terhadap situasi ujian yang dilaksanakan dalam konteks sekolah akan lebih baik dari pada intervensi klinis yang dilaksanakan hanya setelah kecemasan ujian telah muncul sebagai masalah. Asumsi kedua yaitu intervensi setelah murid mengalami kegagalan kecemasan menghadapi ujian dapat meningkatkan resiko stres pada murid.

SIT (Meichenbaum, 1977) merupakan teknik yang mengajarkan keterampilan koping yang berdasarkan pada pendekatan kognitifperilaku. Pendekatan kognitif memiliki hubungan yang kuat dengan terapi perilaku, seperti halnya "mengatur kembali pikiran secara rasional dan sistematis”, mengajarkan individu untuk memodifikasi kalimat internal (pikiran) dan kemudian berlatih analisis pikiran rasional sejalan dengan bermain peran dan latihan perilaku. Konsep ini menyatakan bahwa perubahan kognitif dan perilaku saling memperkuat. Ketika perubahan kognitif menyebabkan perubahan dalam tindakan dan perilaku, tercipta rasa kesejahteraan yang dapat memperkuat perubahan dalam pikiran dan pada akhirnya semakin memperkuat perubahan perilaku (Milkman \& Wanberg, 2007).

Berikut ini hasil penelitian yang mendukung keberhasilan SIT dalam mengurangi kecemasan situasi evaluatif dalam lingkup bidang pendidikan. Saunders, Driskell, Johnston, dan Salas (1996) memperoleh hasil penelitian bahwa SIT memberikan efek positif yang kuat untuk mengurangi perilaku kecemasan, mengurangi kecemasan sesaat, dan meningkatkan hasil belajar dalam keadaan tertekan.

Kiselica, Baker, Thomas, dan Reedy (1994), menerapkan SIT dan menggabungkannya dengan pelatihan asertif (assertiveness training) sebagai program preventif yang terdiri dari 8 sesi yang diterapkan pada subjek remaja di Australia. Hasil penelitian menunjukan SIT dapat memberikan kemajuan yang sangat signifikan dalam mengurangi kecemasan dan stres. Sheehy dan Horan (2004), mengukur efektivitas SIT terhadap kecemasan, stres, pikiran tidak rasional, dan hasil akademik mahasiswa hukum pada tahun pertama. Mahasiswa yang menerima SIT menunjukan penurunan tingkat stres dan emosi yang stabil daripada kelompok kontrol. Mahasiswa juga menunjukan level kecemasan, stres, dan pikiran tidak rasional yang lebih rendah. Dari hasil penelitian tersebut dapat diambil kesimpulan bahwa SIT dapat membantu mengurangi kecemasan menghadapi situasi evaluatif di sekolah seperti UN.

Berdasarkan berbagai penelitian tersebut yang telah membuktikan efek positif dari SIT maka dapat dijadikan acuan untuk menerapkan SIT dalam menurunkan kecemasan menghadapi UN di Indonesia. Hasil penelitian di Indonesia, SIT telah diterapkan pada penelitian Prawesti (2008), Hoedaya (2007), dan Aryani (2009). Pelatihan manajemen stres diharapkan dapat membantu murid untuk berpikir positif mengenai situasi UN dengan cara murid melihat sumber daya pribadi dan menerapkan berbagai strategi koping. Tujuan dari penelitian yaitu melakukan uji coba pelatihan manajemen stres berdasarkan prosedur SIT pada murid SMP yang mengalami kecemasan menghadapi UN. Hipotesis penelitian yaitu pelatihan manajemen stress berdasarkan prosedur SIT dapat menurunkan kecemasan menghadapi UN pada murid SMP. Murid SMP 
yang mendapatkan pelatihan manajemen stres mengalami penurunan tingkat kecemasan menghadapi UN dibandingkan dengan murid yang tidak mendapatkan pelatihan manajemen stres.

\section{METODE PENELITIAN}

Subjek penelitian yaitu murid kelas IX SMP Negeri Kupang, Nusa Tenggara Timur (NTT) yang mengalami kecemasan menghadapi UN. Kriteria dari subjek penelitian: Usia 13-15 tahun, murid SMP Negeri yang akan menghadapi Ujian Nasional, bersedia mengikuti proses penelitian, ditunjukan dari inform concent, berdasarkan hasil skala kecemasan menghadapi UN, murid mengalami kecemasan pada kategori tinggi dengan skor $\geq 99$.

Penentuan kelompok penelitian dilakukan dengan acak. Kelompok eksperimen adalah kelompok yang mendapatkan intervensi berupa pelatihan manajemen stres, sedangkan kelompok kontrol menggunakan model waiting-list (kelompok diberikan perlakuan segera setelah pengukuran berakhir).

Instrumen penelitian yang digunakan untuk mengukur perubahan atau menurunnya kecemasan murid SMP yaitu skala kecemasan menghadapi UN (Nurlaila, 2010). Validitas skala kecemasan menghadapi UN (validitas isi) diukur dengan melihat perilaku yang diamati telah sesuai dengan kerangka teori Anderson (1999); Ergene (2003); Spielberger \& Vagg (dalam Elliot dan Gregor 1999). Reliabilitas skala setelah uji coba menunjukan koefisien alpha sebesar 0,862 . Skala kecemasan akan diberikan kepada semua partisipan pelatihan saat pretest, postest, dan follow-up.

Modul program pelatihan manajemen stres adalah panduan untuk melaksanakan program pelatihan manajemen stres sekaligus menjadi alat instrumen. Modul disusun berdasarkan SIT (Meichenbaum, 1985) dan pandangan transaksional stres dan penyesuaian (coping)
(Lazarus \& Folkman, 1984).

Desain penelitian menggunakan kuasi eksperimen Untreated Control Group Design with Dependent Pretest and Posttest Samples (Shadish, Cook, \& Campbell, 2002). Analisis kuantitatif untuk menguji hipotesis yaitu mixed between-within anava atau disebut sebagai anava campuran. Dalam penelitian ini dikembangkan suatu program pelatihan manajemen stress yang disusun berdasarkan SIT (Stress Inoculation Training) yang telah dipelopori oleh Meichenbaum (1985). SIT diadopsi berdasarkan pandangan transaksional dari stres dan penyesuaian (coping) milik Lazarus dan Folkman (1984). Pandangan ini mengemukakan bahwa stres terjadi ketikatuntutan dari lingkungan (keluarga, sekolah, komunitas) dipersepsikan berlebihan dari sumber daya individu. Pandangan transaksional menganggap stres terjadi karena adanya interaksi dari lingkungan dan karakteristik individu. Pelatihan manajemen stres merupakan program preventif, terdiri atas 3 fase yang saling terkait dan menyambung (Meichenbaum, 1985) yaitu Fase penjelasan konsep (conceptual educational phase), Fase latihan dan pengembangan keterampilan (skills development and practice phase), Fase aplikasi dan follow up (application and follow-up phase).

Pelatihan manajemen stres dipandu oleh seorang trainer yang berpengalaman dan memiliki kompetensi di bidang psikologi. Seleksi trainer dengan kriteria lulusan magister psikologi UGM, mempunyai pengalaman melatih murid SMP Negeri, dan mempunyai pengetahuan di bidang psikologi pendidikan khususnya tentang kecemasan menghadapi UN. Trainer berperan memimpin seluruh sesi pelatihan, memberikan materi pelatihan lengkap dengan instruksi, cara pengerjaan, pelaksanaan, membuat peserta merasa nyaman mengikuti pelatihan, dan menjawab pertanyaan peserta. Trainer dibantu oleh tim yang terdiri dari 4 orang (satu orang fasilitator dan 3 orang observer). 


\section{HASIL DAN PEMBAHASAN}

Dari tabel 1 dapat diketahui bahwa terdapat interaksi antara waktu (pre-pos) dengan kelompok (eksperimen-kontrol), terlihat dari nilai $\mathrm{F}=17,192$ dan Sig. 0,001 ( $<<0,01)$. Interaksi menunjukkan bahwa ada penurunan skor kecemasan berbeda secara sangat signifikan dari waktu pre menuju post pada kedua kelompok (eksperimen-kontrol). Intervensi (pelatihan manajemen stres) secara signifikan dapat menurunkan skor kecemasan menghadapi UN pada kelompok eksperimen, sedangkan kelompok kontrol (tidak mendapat intervensi) tidak menunjukan penurunan skor kecemasan yang signifikan. Hal ini berarti hipotesis penelitian yang menyatakan bahwa pelatihan manajemen stres berdasarkan prosedur SIT dapat menurunkan kecemasan menghadapi UN pada kelompok eksperimen dapat diterima.
Pada tabel 2, menunjukkan bahwa penurunan skor kecemasan pada kelompok eksperimen adalah sangat signifikan ( $M D=35,625 ; \mathrm{p}<0,01$ ) sedangkan penurunan tingkat kecemasan pada kelompok kontrol adalah tidak signifikan ( $M D=3,750 ; p>0,05)$. Hal ini menunjukkan bahwa pelatihan manajemen stres yang diberikan kepada kelompok eksperimen efektif dalam menurunkan kecemasan murid SMP dalam menghadapi UN. Nilai MD dari postes ke follow-up yaitu 3,0, dengan $\mathrm{p}>0,05$. Dari postes ke follow-up, penurunan skor kecemasan tidak signifikan. Hal ini berarti setelah satu bulan, pelatihan manajemen stres masih memiliki pengaruh dalam mengurangi kecemasan menghadapi UN pada murid SMP Negeri Kupang

Tabel 1. Uji interaksi skor kecemasan menghadapi UN

\begin{tabular}{|c|c|c|c|c|c|c|c|}
\hline Source & & $\begin{array}{l}\text { Type III Sum } \\
\text { of Squares }\end{array}$ & Df & $\begin{array}{l}\text { Mean } \\
\text { Square }\end{array}$ & $\mathbf{F}$ & Sig. & $\begin{array}{c}\text { Partial } \\
\text { Eta Squared }\end{array}$ \\
\hline \multirow[t]{4}{*}{ Time } & $\begin{array}{l}\text { Sphericity } \\
\text { Assumed }\end{array}$ & 4095,375 & 2 & 2047,688 & 30,406 & ,000 & , 685 \\
\hline & $\begin{array}{l}\text { Greenhouse } \\
\text { Geisser }\end{array}$ & 4095,375 & 1,122 & 3650,127 & 30,406 & ,000 & ,685 \\
\hline & Huynh-Feldt & 4095,375 & 1,239 & 3306,250 & 30,406 & ,000 & ,685 \\
\hline & Lowerbound & 4095,375 & 1,000 & 4095,375 & 30,406 & 000 & ,685 \\
\hline \multirow[t]{4}{*}{ time*group } & $\begin{array}{l}\text { Sphericity } \\
\text { Assumed }\end{array}$ & 2315,625 & 2 & 1157,813 & 17,192 & ,000 &, 551 \\
\hline & $\begin{array}{l}\text { Greenhouse } \\
\text { Geisser }\end{array}$ & 2315,625 & 1,122 & 2063,871 & 17,192 & ,001 &, 551 \\
\hline & Huynh-Feldt & 2315,625 & 1,239 & 1869,434 & 17,192 & ,000 & , 551 \\
\hline & Lowerbound & 2315,625 & 1,000 & 2315,625 & 17,192 & ,001 & , 551 \\
\hline \multirow[t]{4}{*}{ Error(time) } & $\begin{array}{l}\text { Sphericity } \\
\text { Assumed }\end{array}$ & 1885,667 & 28 & 67,345 & & & \\
\hline & $\begin{array}{l}\text { Greenhouse } \\
\text { Geisser }\end{array}$ & 1885,667 & 15,708 & 120,047 & & & \\
\hline & Huynh-Feldt & 1885,667 & 17,341 & 108,737 & & & \\
\hline & Lowerbound & 1885,667 & 14,000 & 134,690 & & & \\
\hline
\end{tabular}


Tabel 2. Uji perbandingan selisih rerata-rata skor kecemasan menghadapi UN

\begin{tabular}{|c|c|c|c|c|c|c|c|}
\hline & & & $\begin{array}{c}\text { Mean } \\
\text { Difference }\end{array}$ & & & $\begin{array}{r}95 \% \mathrm{Co} \\
\text { Interval for }\end{array}$ & $\begin{array}{l}\text { nce } \\
\text { rence(a) }\end{array}$ \\
\hline $\begin{array}{c}\text { Group ti } \\
\text { Time }\end{array}$ & ne (I) & & $\begin{array}{c}\text { Difference } \\
\text { (IJ) }\end{array}$ & Std.Error & Sig.(a) & Lower Bound & Upper \\
\hline Eksperimen & 1 & 2 & $35,625(*)$ & 5,517 & ,000 & 23,792 & 47,458 \\
\hline & & 3 & $32,625\left(^{*}\right)$ & 3,909 & ,000 & 24,240 & 41,010 \\
\hline & 2 & 1 & $-35,625\left(^{*}\right)$ & 5,517 & ,000 & $-47,458$ & $-23,792$ \\
\hline & & 3 & $-3,000$ & 2,187 & 192 & $-7,691$ & 1,691 \\
\hline & 3 & 1 & $-32,625(*)$ & 3,909 & ,000 & $-41,010$ & $-24,240$ \\
\hline & & 2 & 3,000 & 2,187 & 192 & $-1,691$ & 7,691 \\
\hline Kontrol & 1 & 2 & 3,750 & 5,517 & ,508 & $-8,083$ & 15,583 \\
\hline & & 3 & 6,375 & 3,909 & 125 & $-2,010$ & 14,760 \\
\hline & 2 & 1 & $-3,750$ & 5,517 & ,508 & $-15,583$ & 8,083 \\
\hline & & 3 & 2,625 & 2,187 & ,250 & $-2,066$ & 7,316 \\
\hline & 3 & 1 & $-6,375$ & 3,909 & 125 & $-14,760$ & 2,010 \\
\hline & & 2 & $-2,625$ & 2,187 & 250 & $-7,316$ & 2,066 \\
\hline
\end{tabular}

Analisis kualitatif dilakukan pada kelompok eksperimen berdasarkan diskusi kelompok, observasi proses pelatihan, observasi individu, dan lembar kerja subjek. Analisis kualitatif membahas dinamika psikologis pada individu. Subjek di kelompok eksperimen yang menunjukkan penurunan skor kecemasan paling menonjol (tingkat kecemasan rendah) adalah subjek Ps (skor awal 99, turun 65 poin), Mnm (skor awal 99, turun 53 poin), dan $\mathrm{Nb}$ (skor awal 100, turun 52 poin). Selain itu, subjek yang menunjukan penurunan skor kecemasan pada tingkat sedang yaitu subjek Rm (skor awal 102, turun 41 poin), Aa (skor awal 100, turun 35 poin), dan Et (skor awal 99, turun 21 poin). Subjek kelompok eksperimen yang menunjukan penurunan skor kecemasan yang kurang menonjol yaitu subjek Eyn (skor awal 102, turun 6 poin) dan Frld (skor awal 99, turun 12 poin).

Penelitian ini bertujuan untuk melakukan uji coba pelatihan manajemen stress berdasarkan prosedur SIT pada murid SMP yang mengalami kecemasan menghadapi UN. Pelatihan manajemen stres sebagai salah satu program preventif diharapkan dapat menurunkan kecemasan murid SMP dalam menghadapi UN.
Berdasarkan hasil yang telah dipaparkan, pelatihan manajemen stres mampu menurunkan tingkat kecemasan menghadapi UN pada murid SMP Negeri Kupang (kelompok eksperimen). Hasil analisis menunjukan bahwa ada perbedaan secara signifikan pada penurunan skor kecemasan menghadapi UN pretes menuju postes antara kelompok eksperimen yang mendapatkan pelatihan manajemen stres dengan kelompok kontrol yang tidak mendapatkan pelatihan $(\mathrm{F}=17,192$ dan $\mathrm{p}<0,01)$. Pelatihan manajemen stres disusun berdasarkan prosedur SIT yang telah dipelopori oleh Meichenbaum (1985). SIT merupakan teknik yang mengajarkan keterampilan koping berdasarkan pendekatan kognitif-perilaku (Meichenbaum, 1977).

Pelatihan manajemen stres menggunakan pendekatan kognitif behavioral (Meichenbaum, 1985). Prinsip pendekatan ini yaitu kognisi murid mempunyai peran yang signifikan dalam perkembangan dan pengelolaan reaksi emosi dan perilaku terhadap situasi UN. Proses kognisi seperti memberikan arti, penilaian, dan asumsi memainkan peran signifikan dalam perubahan reaksi emosi dan perilaku. Menurut Milkman dan Wanberg (2007), perubahan kognitif dan 
perilaku saling memperkuat. Perubahan kognitif menyebabkan perubahan dalam tindakan dan perilaku, tercipta rasa kesejahteraan yang dapat memperkuat perubahan dalam pikiran dan pada akhirnya semakin memperkuat perubahan perilaku. Hal ini sesuai dengan pendapat yang mengatakan bahwa pendekatan kognitif behavioral merupakan perlakuan yang efektif untuk mengatasi kecemasan terhadap ujian (Neuderth, Jabs, \& Schmidtke, 2009; Ergene, 2003).

Kelompok eksperimen yang diberikan pelatihan manajemen stres mengalami perubahan pola pikir (pandangan) menjadi lebih positif terhadap situasi UN. Sebelum mendapat pelatihan, subjek mempunyai pemikiran UN menakutkan, menekan, menegangkan, dan ada perasaan tidak mampu menghadapi situasi UN. Sesudah mendapat pelatihan, subjek mempunyai pemikiran bahwa UN merupakan tantangan yang harus dihadapi. Subjek yakin dapat menghadapi UN dengan berdoa, belajar lebih giat, menambah jam belajar, mengerjakan tugas rumah, dan menuntaskan nilai pelajaran. Selain itu, dengan menerapkan berbagai strategi koping seperti koping yang berfokus pada masalah dan koping yang berfokus pada emosi membuat subjek semakin yakin dapat menghadapi UN. Hasil penelitian ini sejalan dengan penelitian Meichenbaum (1993) yang telah berhasil menerapkan SIT untuk mengurangi kecemasan menghadapi situasi evaluatif, salah satunya situasi ujian.

Berikut ini penjabaran hasil penelitian sebelumnya yang mendukung hipotesis penelitian. Hains \& Szyjakowski (1990); Hains \& Ellmann (1994) menguji efektifitas SIT berdasarkan Meichenbaum model 1985 kepada kelompok remaja yang mengalami kecemasan berlebihan berkaitan dengan situasi stres. Hasil menunjukan bahwa kelompok pelatihan menunjukan pengurangan yang signifikan pada level kecemasan dan marah, meningkatkan harga diri, dan berpikir positif ketika menghadapi situasi yang menekan. Saunders, dkk (1996) memperoleh hasil penelitian bahwa SIT memberikan efek positif yang kuat untuk mengurangi perilaku kecemasan, mengurangi kecemasan sesaat, dan meningkatkan hasil belajar dalam keadaan tertekan. Penelitian Kiselica, dkk (1994) menunjukan SIT dapat memberikan kemajuan yang sangat signifikan dalam mengurangi kecemasan dan stres pada subjek remaja di Australia.

Keberhasilan pelatihan manajemen stres dalam menurunkan kecemasan menghadapi UN dapat terjadi karena modul dan materi pelatihan yang berisi pandangan transaksional tentang stres dan penyesuaian (coping skill) (Lazarus \& Folkman, 1984). Pandangan ini mengemukakan bahwa kecemasan menghadapi UN akan terjadi bila individu mengalami stres yang berlebihan karena tuntutan dari lingkungan (keluarga, sekolah, dan masyarakat) dipersepsikan berlebihan dari sumber daya individu. Proses kognisi dan aktivitas koping memainkan peran penting untuk menyeimbangkan tuntutan lingkungan dengan sumber daya individu. Prinsip dasar pandangan transasional yaitu tujuan personal, nilai, dan keyakinan dapat menentukan terjadinya kecemasan menghadapi UN. Karena itu, modul pelatihan ini dirancang untukmengubah pikiran negatif murid tentang situasi UN yang menekan dan menakutkan menjadi hal yang menantang.

Lazarus (1991) mengatakan mekanisme kecemasan menghadapi UN terjadi berdasarkan penilaian kognitif dan koping dari murid. Penilaian kognitif merupakan interpretasi yang diberikan pada situasi UN dan sebagai penentu intensitas emosi dan perilaku (Lazarus \& Folkman, 1984). Penilaian kognitif terdiri atas dua tahap yaitu penilaian primer dan sekunder. Penilaian primer peserta pelatihan yaitu situasi UN dianggap membahayakan dan mengancam tujuan personal murid untuk lulus UN. Penilaian sekunder peserta pelatihan yaitu mereka berpikir tidak memiliki sumber daya yang memadai untuk menghadapi situasi UN. 
Menurut Lazarus dan Folkman (1984), koping diperkirakan dapat membantu murid beradaptasi dengan situasi stres dan kecemasan. Koping juga melibatkan murid untuk berubah secara kognitif dan perilaku sebagai upaya untuk mengelola tuntutan internal dan eksternal. Koping terdiri atas dua jenis yaitu koping yang berfokus pada masalah dan emosi. Hal tersebut sejalan dengan penelitian Stowell, dkk (2008) mengemukakan bahwa murid dengan kecemasan ujian yang tinggi gagal dalam menggunakan strategi koping. Murid yang menggunakan koping berfokus pada emosi dan masalah secara bersamaan menunjukan penyesuaian diri yang lebih baik daripada murid yang hanya menggunakan salah satu jenis koping (Kraag, dkk 2009). Oleh karena itu, selain diberikan materi tentang stres peserta juga diberikan pengetahuan tentang koping dan jenis koping agar dapat mengurangi kecemasan menghadapi UN.

Untuk mengubah pikiran dan pemahaman materi, murid dilibatkan dengan aktivitas seperti ceramah, diskusi, roleplay, dan mengisi lembar kerja. Selain itu, proses pelatihan diselingi dengan adanya ice breaking, video, tayangan presentasi, dan cerita perumpamaan, yang dapat berguna membangun suasana santai, menyenangkan, dan menarik perhatian sehingga murid lebih mudah untuk fokus, memahami dan menyerap materi pelatihan, serta bersemangat menjalani aktivitas pelatihan. Menurut Silberman (1998), aktivitas tersebut merupakan pembelajaran melalui pengalaman. Pembelajaran melalui pengalaman adalah metode yang paling efektif untuk meningkatkan pemahaman dalam proses pelatihan, karena proses belajar yang terjadi melibatkan individu untuk memperhatikan, menganalisis, mencari pemahaman, dan kemudian menerapkan pengetahuan dan pemahaman tersebut dalam perilaku.

Keberhasilan pelatihan manajemen stres juga tidak lepas dari peran pengalaman trainer. Tidak jarang trainer mengimprovisasi materi yang disampaikan sehingga pesannya ditangkap oleh subjek. Trainer mampu memberikan contoh konkrit menghadapi stres dan pelaksanaan strategi koping dalam kehidupan sehari-hari remaja. Faktor keberhasilan berikutnya adalah pelatihan manajemen stres dilakukan dengan metode kelompok seperti mendengar pengalaman peserta lain sehingga peserta merasa tidak sendiri menghadapi masalah UN. Menurut Yalom (2005), dalam kelompok akan terjadi pencerahan (insight), menerima sugesti, dukungan, pemberian keyakinan, dan dapat berbagi masalah dengan orang lain. Prawitasari (1992) juga menambahkan keuntungan peserta berada dalam kelompok karena dapat saling memberi umpan balik, mendapat kesempatan belajar dan berlatih keterampilan baru, serta belajar saling mengekspresikan perasaan.

Selain itu, jumlah peserta dalam kelompok juga terlibat dalam proses dinamika kelompok. Pada pelatihan ini, jumlah peserta 8 murid pada kelompok eksperimen dan murid pada kelompok kontrol. Ketika jumlah peserta tidak banyak maka seluruh peserta dalam kelompok mempunyai kesempatan untuk mengungkapkan perasaan dan umpan balik. Yalom (2005) mengatakan jumlah peserta dalam kelompok yang efektif yaitu tujuh hingga dua belas peserta. Peneliti melakukan evaluasi reaksi peserta terhadap pelaksanaan pelatihan. Hasil evaluasi menunjukan bahwa pelatihan manajemen stres mendapatkan respon dari peserta dengan skor rata-rata 4,3 (dari skala 5). Hal ini menunjukan bahwa aspek-aspek pelatihan seperti pelaksanaan pelatihan secara keseluruhan, tempat (ruang), peralatan, konsumsi, suasana selama pelatihan, dan pengaturan waktu dianggap puas oleh subjek. Aspek penilaian yang mendapatkan skor rata-rata paling rendah yaitu ruangan $(3,5)$ dan pengaturan waktu $(3,87)$. Hal ini karena, pada pertemuan kedua terjadi pemindahan ruangan. Suhu di dalam ruangan yang cukup panas membuat peserta maupun fasilitator berkeringat. 
Hasil evaluasi reaksi peserta terhadap pembicara (trainer\&fasilitator) mendapatkan skor rata-rata 4,45 (dari skala 5). Hal ini menunjukan bahwa aspek-aspek pembicara seperti gaya menyampaikan materi, gaya memimpin diskusi, dan gaya menjawab pertanyaan murid dianggap menarik oleh peserta. Peserta menilai bahwa trainer mampu untuk menyampaikan materi dengan jelas dan menarik. Peserta menilai semua materi yang diberikan selama pelatihan sangat bermanfaat ketika menghadapi UN. Setelah mendapakan berbagai materi pelatihan, peserta berpikir bahwa UN tidak perlu ditakutkan melainkan dianggap sebagai tantangan yang bisa dihadapi. Evaluasi dari observer mengamati bahwa semua peserta tampak antusias dalam mengikuti pelatihan dan beberapa peserta tampak lebih aktif dari yang lainnya pada sesi diskusi dan tanya-jawab.

\section{SIMPULAN}

Hasil penelitian menunjukkan bahwa pelatihan manajemen stres mampu menurunkan tingkat kecemasan menghadapi UN pada murid SMP Negeri Kupang, dan ada perbedaan secara signifikan pada penurunan skor kecemasan menghadapi UN dari pretes menuju pos-tes antara kelompok eksperimen yang mendapatkan pelatihan manajemen stres dengan kelompok kontrol yang tidak mendapatkan pelatihan. Pelatihan manajemen stres berdasarkan prosedur SIT dapat digunakan untuk menurunkan kecemasan menghadapi UN pada murid SMP. Hal ini karena pelatihan manajemen stres dapat mengubah penilaian kognitif dan penilaian sumber daya (koping) yang dimiliki murid ke arah yang positif.

\section{DAFTAR PUSTAKA}

Azwar, S. (2012). Penyusunan skala psikologi edisi 2. Pustaka Pelajar: Yogyakarta.
Aryani, F. (2009). Efektivitas pendekatan cognitive behavior modification (cbm) untuk mengelola stres belajar siswa (Disertasi tidak dipublikasikan). Program Studi Bimbingan dan Konseling Universitas Negeri Malang, Malang.

Elliot, S. M., Kratochwill, T. R., Littlefield, J., \& Travers, J. F. (1999). Educational psychology:effective teaching effective learning. Singapore: Mc Graw Hill Book Company.

Ergene, T. (2003). Effective interventions on test anxiety reduction. Journal School Psychology International, 24 (3), 313-329.

Griffith, M. A., Dubow, E. F., \& Ippolito, M. F. (2000). Developmental and crosssituational differences in adolescents coping strategies. Journal of youth and adolescence, 29 (2), 183-205.

Hains, A. A., \& Ellmann, S. W. (1994). Stress inoculation training as a preventative intervention for high school youths. Journal of Cognitive Psychotherapy, 8, 219"232.

Hains, A. A., \& Szyjakowski, M. (1990). A cognitive stress-reduction intervention program for adolescents. Journal of Counseling Psychology, 37, 79"84.

Hembree, R. (1988). Correlates, cause, effect and treatment of test anxiety. Review of educational research, 58 (1): 4777.

Hoedaya, D. (2007). Manajemen stres atlet olahraga beregu. Jurnal Iptek Olahraga, 9 (1), 1-17.

Kiselica, M. S., Baker, S. B., Thomas, R. N., \& Reedy, S. (1994). Effects of stress 
inoculation training on anxiety, stress, and academic performance among adolescents. Journal of Counseling Psychology, 41, 335-342.

Kraag, G., Gerard, J. P., Breukelen, V., Kok,G., \& Hosman, C. (2009). Learn young, learn fair, a stress management program for fifth and sixth graders: longitudinal results from an experimental study. Journal of Child Psychology and Psychiatry, 50 (9), 1185-1195, doi:10.1111/j.14697610.2009.02088.x.

Lazarus, R.S., \& Folkman, S. (1984). Stress, appraisal, and coping. New York: Springer.

Lazarus, R. S. (1990). Theory-based stress measurement. Psychological Inquiry, 1, 3-13.

Lazarus, R. S. (1991). Emotion and adaptation. New York: University Press.

Meichenbaum, D. H. (1993). Stress inoculation training: a twenty year update. In R. L.

Meichenbaum, D. H. (1985). Stress inoculation training. Elmsford, NY: Pergamon Press.

Meichenbaum, D. H., \& Deffenbacher, J. L. (1988). Stress inoculation training. The Counseling Psychologist, 16, 69-90.

Meichenbaum, D. (1977). Cognitive-behaviour modification: an integrative approch. New York: Plenum Press.

Milkman, H., \& Wanberg, K. (2007). Cognitive-behavioral treatment, a review and discussion for corrections professionals. National
Institute of Corrections: Colorado.

Neuderth, S., Jabs, B., \& Schmidtke, A. (2009). Strategies for reducing test anxiety and optimizing exam preparation in German university students: a prevention-oriented pilot project of the University of Wu"rzburg. Journal Neural Transmition, 116, 785-790, doi 10.1007/s00702-008-0123-7.

Nurlaila, S. (2010). Pelatihan efikasi diri untuk menurunkan kecemasan pada siswa-siswi yang akan menghadapi ujian akhir nasional (Tesis tidak dipublikasikan). Magister Profesi Psikologi Universitas Gadjah Mada, Yogyakarta.

Peraturan Menteri Pendidikan dan Kebudayaan Nomor 59 tahun 2011 Tentang Kriteria kelulusan peserta didik dari satuan pendidikan Dan penyelenggaraan ujian sekolah/ madrasah dan ujian Nasional. Diunduh dari http//www.bnsp.go.id.

Prawesti, N. A. (2008). Penggunaan prolonge expire dan stress inoculation training pada remaja yang menderita amite stress disorder (asd) akibat perkosaan (Tesis tidak dipublikasikan). Fakultas Psikologi Universitas Airlangga, Surabaya.

Santrock, J. (2007). Adolescence 8th ed. McGraw-Hill International Edition. New York: University of Texas at Dallas.

Sarason, I. G. (1984). Stress, anxiety, and cognitive interference: Reactions to Tests. Journal of Personality and Social Psychology, 46, 929-938.

Saunders, T., Driskell, J. E., Johnston, J. H., \& 
Salas, E. (1996). The Effect of stress inoculation training on anxiety and performance. Journal of Occupational Health Psychology, 1(2), 170-186.

Shadish, W. R., Cook, T. D., \& Campbell, D. T. (2002). Experimental and quasiexperimental designs for generalized causal inference. Houghton Mifflin Co: Boston.

Sheehy, R., \& Horan, J. J. (2004). Effects of stress inoculation training for 1st-year law students. International Journal of Stress Management, 11 (1), 4155, DOI:10.1037/10725245.11.1.41.

Silberman, M. (1998). Active training: a handbook of techniques, design, case examples, and tips. San fransisco: Jossey-Bass. Spielberger, C. D. (1966). Anxiety and behavior. New York : Academic Press.

Spielberger, C. D. (1972). Curent trends in theory and research on anxiety. New York: Academic Press.
Spielberger, C. D. (1983). Manual for the state-trait anxiety inventory (STAI). PaloAlto, CA: Consulting Psychologists Press.

Stowell, J.R, Tumminaro, T,. \& Attarwala, M (2008). Moderating effects of coping on The Relationhip between Test Anxiety And Negatif Mood. Stress and Health. Vol.4. 313-321.

Suryani, Y. (2012). Program bimbingan kelompok untuk meningkatkan kemampuan siswa mengelola stres sekolah: studi kuasi eksperimen terhadap siswa kelas $X$ (Tesis tidak dipublikasikan). Program Studi Bimbingan dan Konseling Universitas Pendidikan Indonesia, Bandung.

Yalom, I. D. (2005). The theory and practice of group psychoterapy: fifth edition. USA: Basic books, Inc.

Zeidner, M. (1998). Test anxiety: the state of the art. New York: Kluwer Academic Publishers. 
92 